Tantasavasdi, C., Srebric, J., and Chen, Q. 2001. "Natural ventilation design for houses in Thailand," Energy and Buildings, 33(8), 815-824.

\title{
Natural Ventilation Design for Houses in Thailand
}

\author{
Chalermwat Tantasavasdi $^{\text {a }}$, Jelena Srebric ${ }^{\mathbf{b}}$, Qingyan Chen ${ }^{\mathrm{c}^{*}}$ \\ ${ }^{a}$ Architecture Program, Thammasat University, Room 713 Faculty of Engineering \\ Building, Rangsit Campus, Pathumthani 12121, Thailand \\ ${ }^{b}$ Department of Architectural Engineering, The Pennsylvania State University, 222 \\ Engineering Unit A, University Park, PA 16802, USA \\ ${ }^{c}$ Building Technology Program, Department of Architecture, Massachusetts Institute of \\ Technology, Room 5-418, 77 Massachusetts Avenue, Cambridge, MA 02139, USA \\ *Phone: (617) 253-7714, Fax: (617) 253-6152, Email: qchen@mit.edu
}

\begin{abstract}
This paper explores the potential of using natural ventilation as a passive cooling system for new house designs in Thailand. The characteristics of past and present Thai houses are analyzed in terms of climate, culture, and technology. Based on the thermal comfort requirements for the Thai people and the climate conditions in Bangkok, the study found that it is possible to use natural ventilation to create a thermally comfortable indoor environment in houses in a Bangkok suburb during 20\% of the year. This study also develops comprehensive design guidelines for natural ventilation at both the site planning and individual house levels by using computational fluid dynamics.
\end{abstract}

Keywords: Natural ventilation; Computational Fluid Dynamics; Air velocity; Thermal comfort; House; Thailand

\section{Introduction}

Natural ventilation has served as an effective passive cooling design strategy to reduce energy used by air-conditioning systems. For tropical regions, where the air temperature and relative humidity are generally high, the effectiveness of natural ventilation is always questionable. The vernacular architecture of Thailand, such as the traditional Thai house in Fig. 1a, was designed to take advantage of the prevailing winds. The traditional Thai house is normally built with three notable characteristics: an elevated floor, a steeply pitched roof with long overhangs, and a large open terrace. The elevated floor prevents sudden flooding, protects occupants from dangerous animals, and allows more wind to flow through the living space. The long overhangs provide shade protect the house from rain. There is a thermal stratification in the house; the air temperature in the lower part of the house is lower than that in the upper part. The occupant usually stays in the lower, more comfortable part of the space. The large open terrace, which occupies approximately $40 \%$ of the total floor area, serves as a space for outdoor activities, and was an important space for the typical extended families of the Thai people of the past.

Lives in the past two decades have changed dramatically. People tend to be more accustomed to air-conditioned environments. Nearly all cars, urban offices, schools, and houses are air-conditioned if the owner can afford one. About $90 \%$ of urban indoor environments are air-conditioned. However, people are concerned with the rising costs of electricity and fuel, especially when they have to pay utility bills for their own residences. In suburban houses, air-conditioning is used during the hot hours of the days. During the 
cooler hours, most people are still willing to open their windows and let fresh air in. Therefore, almost all windows in suburban houses can be opened.

Passive cooling design elements are mostly ignored in modern house designs (Fig. 1b). Dense areas in large cities such as Bangkok create a hot microclimate and discourage the use of natural ventilation because the buildings block each other from the wind. Current designs used many ideas and building materials from Europe and America without careful consideration for the Thai climate. For example, most new houses have no overhangs, resulting in easy penetration of the sun into the living area. The building envelopes are made of materials with a high thermal mass, such as concrete and brick. These materials store a large amount of heat during the day, and transfer it into the living space at night. As a result, houses are too hot without the assistance of an air-conditioner.

The problems with current designs have prompted designers to rethink their designs, especially because of an increasing awareness of sustainability. To conserve energy and reduce $\mathrm{CO}_{2}$ emissions, it is important to design energy-efficient buildings. This paper explores the potential to reduce energy consumed by air-conditioners through the use of natural ventilation in building design.

\section{Thermal Comfort Analysis}

In addition to the difference between traditional Thai and modern western houses, the comfort expectations of westerners and the Thai may be different. It is important to understand the Thai's thermal comfort expectations in order to design a proper ventilation system. The ASHRAE Standard 55a-1995 on "Thermal Environmental Conditions for Human Occupancy” gives the upper limit of comfortable temperature as $26^{\circ} \mathrm{C}$, and the wet bulb temperature upper limit as $20^{\circ} \mathrm{C}$ [1], as shown in Fig. 2. However, many studies have concluded that the comfort temperature is higher in tropical regions, since humans have the ability to acclimatize and/or have physiological variation [2]. Field study results show the discrepancies between thermal comfort requirements of the Thai people and westerners. Busch's study [3] shows that, based on $80 \%$ of Thai workers being satisfied, the upper limit of the comfortable temperature can be as high as $28^{\circ} \mathrm{C}$ for people in airconditioned buildings, and $31^{\circ} \mathrm{C}$ in naturally ventilated buildings.

The upper limit of comfortable temperature, which was developed for the $40^{\circ} \mathrm{N}$ latitude, can be $1.0 \mathrm{~K}$ higher for every 12 degrees change in latitude to the south [4]. Since Bangkok is located at $14^{\circ} \mathrm{N}$ latitude, the corresponding comfort temperature upper limit is $28.2^{\circ} \mathrm{C}$. This temperature is close to that found in Busch's study.

Another experiment by Jitkhajornwanich et al. [5] shows that the upper limit for thermal comfort is as high as $31.5^{\circ} \mathrm{C}$. This result corresponds to Busch's results for the naturally ventilated case.

Kwok [6] conducted a survey of 3,544 students and teachers in 29 naturally ventilated and air-conditioned classrooms in Hawaii. He found that naturally ventilated classroom occupants accept a wide operative temperature range $\left(22.0-29.5^{\circ} \mathrm{C}\right)$.

Based upon the fact that most people now live in air-conditioned spaces, the thermal comfort limit used for the Thai should be that found for the air-conditioned group in Busch's study, $28^{\circ} \mathrm{C}$.

Besides air temperature, strong air movement can increase the rate of convective and evaporative heat loss from the human skin to the environment. Thus, one feels cooler with a higher air velocity. Lechner [7] gives the equivalent temperature reduction (ETR) 
according to air speed. ETR represents the temperature increase necessary to maintain the same thermal sensation with a given air velocity. For example, the ETR is 1.1, 1.9, and $3.3 \mathrm{~K}$ at air velocities of $0.2,0.4$, and $1.0 \mathrm{~m} / \mathrm{s}$, respectively. The upper limit of air movement for an indoor space is $1 \mathrm{~m} / \mathrm{s}$, at which the wind starts to pick up light objects, such as loose paper. The comfort zone can be shifted along the relative humidity line [8]. Therefore, the upper limit at wind speeds of $0.2,0.4$ and $1 \mathrm{~m} / \mathrm{s}$, is $29.1,29.9$ and $31.3^{\circ} \mathrm{C}$, or $23,23.5$ and $24.5^{\circ} \mathrm{C}$ wet-bulb temperature, respectively. These new comfort zones are shown in Fig. 2 for $\mathrm{V}=0.2,0.4$, and $1.0 \mathrm{~m} / \mathrm{s}$. A recent study in Thailand [9] has found similar trends.

Because the Thai have a tolerance for higher air temperatures, there is some potential for using natural ventilation in modern Thai houses through careful design. The following section analyzes if and when natural ventilation can be used in Thailand.

\section{Climate Analysis}

House designs using natural ventilation require appropriate climates. It is well known that natural ventilation can work in a moderate climate, such as those in western and northern Europe, California, and others. However, Thailand is located between the 6 and $20^{\circ} \mathrm{N}$ latitudes, and has a typical tropical climate. In general, Thailand is hot and humid, with small seasonal changes throughout the year. There are three recognizable, although not completely distinct, seasons. The hot summer months from March to June are characterized by a high sun angle, high temperature, and moderate south wind. The rainy season from July to October has a lower temperature but a higher humidity than the summer months. The remaining months, November to February, are the winter months, where the sun angle is the lowest and the temperature is moderate. The air temperature for the year ranges from 21 to $35^{\circ} \mathrm{C}$, while the relative humidity varies from 45 to $95 \%$.

This investigation used metropolitan Bangkok conditions as a reference case. Analysis of ten-year weather data shows that natural ventilation is most suitable for the winter months. Fig. 3 shows a bio-climatic chart of winter temperatures and humidities along with the comfort zones for different indoor air velocities. Each spot on the chart represents the hourly averaged air conditions in Bangkok on a ten-day basis. The averages were taken at the same time over a ten-day period from the ten-year weather database. The air in winter mornings and evenings is already within the comfort zone without the wind effect included

For the rest of the time, appropriate air movement is needed to achieve a comfortable condition. The temperature in some afternoon hours in January and February exceeds $31.3^{\circ} \mathrm{C}$, which is too high for comfort, even with a $1 \mathrm{~m} / \mathrm{s}$ indoor air velocity. The climate can be classified into five groups, as shown in Fig. 3:

1. Hot air; natural ventilation does not work

2. Warm air; high natural ventilation is needed

3. Comfortable air; moderate ventilation is appropriate

4. Humid air; natural ventilation is not appropriate

5. Cool, humid air; minimal ventilation will help

The chart suggests that if the indoor air velocity is $0.4 \mathrm{~m} / \mathrm{s}$, natural ventilation can provide comfort for 1,825 hours per year (approximately $20 \%$ of the time). Although this is not a large number, it is worth to pursuing, because natural ventilation has a very low cost. 
Note that the indoor air temperature is normally higher than the outdoor air temperature, due to internal heat gains and heat transfer through the building enclosure in such a climate. If all the walls are shaded, and the walls and roof insulated with a $0.075 \mathrm{~m}$ thickness of microfiber [10] (the total U-value for the roof and walls is $0.44 \mathrm{~W} / \mathrm{m}^{2}{ }^{\circ} \mathrm{C}$ ), the design cooling load is $4.5 \mathrm{~kW}$ for a typical Thai family home with a floor area of 160 $\mathrm{m}^{2}$. The latent load is about $10 \%$. If the wind inlet apertures in the building are $10 \%$ of the floor area, an average wind velocity of $1.0 \mathrm{~m} / \mathrm{s}$ at the apertures will lead to an indoor air temperature of only $0.2 \mathrm{~K}$ higher than the outdoor air temperature. If the wind velocity at the apertures is reduced to $0.4 \mathrm{~m} / \mathrm{s}$, the temperature difference only increases to $0.5 \mathrm{~K}$. However, if the air velocity is further decreased to $0.1 \mathrm{~m} / \mathrm{s}$, the indoor air temperature will be $2.0 \mathrm{~K}$ higher than the outdoor air temperature, which will eliminate most of benefits of natural ventilation in such a climate.

The above analysis suggests that it is important to know the local wind patterns. The prevailing wind comes from two predominant directions in the winter months. In November and December, the wind is mostly from the north-northeast (NNE) and the north (N). The wind starts to change direction in January to the south-southwest (SSW) and the south (S). The wind direction changes completely into SSW and S in February. The wind speed in the winter months varies from 0.4 to $3.2 \mathrm{~m} / \mathrm{s}$. The five groups of climate conditions shown in Fig. 3 are plotted on a timetable in Fig. 4. Each climate condition is plotted with the corresponding prevailing wind speed. Since group 2 needs maximum ventilation, it is important to have sufficient wind velocities for this group. Fig. 4 indicates that the lowest wind speed for group 2 occurs in the evenings of January and February. The corresponding average wind speed is $1.4 \mathrm{~m} / \mathrm{s}$ from the SSW direction. If a house can provide enough wind under this condition, it can be comfortable for all other conditions except group 1.

\section{Site Planning}

Designing houses with good natural ventilation in urban areas is challenging, because the surroundings have a significant impact on the wind pattern and indoor air velocity. In the downtown area, air pollution and disturbing noises discourage the use of natural ventilation in residential buildings. Therefore, our investigation focuses on suburban residential areas. These suburban houses have a larger potential for taking advantage of the prevailing winds, because of the cleaner and less dense neighborhood environments. In fact, houses in the suburbs are perceived as the norm in modern Thailand.

Most of mater plans at today's typical housing projects do not encourage the use of natural ventilation. Houses with a typical land lot of 240 to $250 \mathrm{~m}^{2}$ are mostly aligned with the street grid. This makes the houses upstream block wind from those downstream. Natural ventilation is not suitable for housing projects with this kind of alignment.

In order to reduce the wind blockage by the houses, they should be staggered to encourage natural ventilation [11]. Linear alignments create a wind shadow, which is a low-pressure area at the back of each house. The best arrangement is to stagger the houses according to the prevailing wind direction. It reduces the wind shadow area at the back of each house, giving the maximum airflow to the downstream houses.

However, solar heat gain plays an equally important role in deciding the house orientation. In order to minimize the solar gain in Thailand, the houses should be oriented 
with long sides facing north and south. If the prevailing wind direction is not north-south, this could creat a possible conflict between these design factors.

In addition to the house orientation, the house width-length ratio can be important in determining the amount of natural ventilation. Olgyay [12] suggests that the optimal ratio for a house in hot and humid climates is $1: 1.7$, with the long sides facing north and south. This design seems appropriate in suburban Bangkok, especially since the prevailing wind is mostly from the NNE and SSW, so there is no conflict between wind alignment and the solar alignment.

In order to study the orientation and ratio, this investigation used computational fluid dynamics (CFD) software [13] to determine airflow through a given site plan. The study considered two site plans. Houses in case 1 (Fig. 5a) are 9 x $9 \mathrm{~m}$ square. In case 2 (Fig. 5b), the houses are rectangular, with a 1:1.7 ratio between the sides. Each floor is 7 $\mathrm{x} 12 \mathrm{~m}$. In both cases, each house has two stories. The CFD analysis used a wind speed of $1.4 \mathrm{~m} / \mathrm{s}$ from the SSW, which is the most critical wind, as described in section 3 . However, most of the winter winds come from the NNE. Despite their different orientations, the prevailing winds from the two directions can be simulated as one case, since they come from the exact opposite directions and the site plan is symmetric.

The CFD simulations modeled several rows of houses in a site. Friction from the terrain creates a velocity gradient in the wind. The wind speed of $1.4 \mathrm{~m} / \mathrm{s}$ is assumed to have been measured at $10 \mathrm{~m}$ above ground level. The simulations used the following wind velocity profile:

$$
\mathrm{U}_{\mathrm{H}}=\mathrm{U}_{\mathrm{ref}} \mathrm{x}\left(\mathrm{H} / \mathrm{H}_{\mathrm{ref}}\right)^{\mathrm{a}}
$$

where $U_{H}$ is the wind velocity at height $H$, and $U_{\text {ref }}$ is the reference wind velocity at height $\mathrm{H}_{\text {ref. }}$ The constant $\mathrm{a}=0.22$.

The CFD simulations used periodic flow boundary conditions in the east and west surfaces, which meant that the houses repeat indefinitely in the east and west directions. The results show that the air velocity at the houses in the downstream rows is much lower than at the upstream rows. However, the velocity stabilizes at the fourth row of houses and beyond, as shown in Fig. 5. This investigation used a house in the fifth row as a reference, since it can be regarded as a typical house in a large housing project.

Although the prevailing wind direction is SSW, the wind direction on the first and second floors is south. This demonstrates that the original wind direction may be unimportant, because the wind direction within the development is shaped by the houses. Of course, this case uses a wind direction that deviates only slightly from the south (no more than $30^{\circ}$ ). If the wind was from the southwest, the scenario could be very different.

In the simulation, the reference house was modeled with all the apertures while the rest were modeled as solid blocks. Zhai et al. [14] found that the impact the apertures on the downstream pressure and wind distribution is minimal, so it is acceptable to simulate surrounding buildings as solid blocks. However, it is necessary to specify the apertures for the house studied (the reference house) in order to determine the natural ventilation rate.

The results show that the wind at the inlets of the reference house in case 1 had an average velocity of $0.4 \mathrm{~m} / \mathrm{s}$. However, the average velocity was reduced to $0.2 \mathrm{~m} / \mathrm{s}$ in case 2. This seems contradictory to the previous study [12], which showed that a 
rectangular building has better natural ventilation than a square building. However, the houses in this study had very small lots. When located on the same land lots, the houses with rectangular shapes had more space at the front and the back than the houses with the square shapes. The distance between the two houses became very small, which blocked the wind from passing through. Therefore, houses with square shapes (case 1) will give a higher air velocity at the apertures than houses with rectangular shapes (case 2). Thus, case 1 is more appropriate for natural ventilation.

\section{House Design}

A prototype for a typical house in Thailand was designed based upon the analysis and results from the site plan. Obviously, Thai houses need two cooling systems: an active system with conventional air-conditioning for the hot months, and a passive system with natural ventilation in the cool months. Air-conditioned buildings should have a compact shape to reduce heat gains, while naturally ventilated buildings should have a large envelope and an irregular shape [15]. Hence, a conflict exists between the design of the air-conditioned and naturally ventilated buildings. Our climate analysis showed that natural ventilation can be used for no more than four months per year in Thailand, so the design should be optimized more for air-conditioning type. Our design has a compact shape to reduce heat gains, but also has large windows for natural ventilation.

Sustainable building design should use good technologies from the vernacular architecture and consider the Thai culture. For example, properly-sized overhangs that can shade the buildings from excessive solar heat gain should be used in new designs. The living and sleeping spaces in the houses should still be on the second level or higher to avoid floods. The ground floor, which can be left open for drainage, could serve as a multipurpose area and/or a car garage. On the other hand, a large, open terrace may not be very necessary in today's society, because Thai families are now mostly nuclear, containing only parents and children. Multi-generational families are diminishing. Therefore, the terrace can be much smaller, allowing for fewer outdoor activities.

Typically, a single Thai family prefers a living area of around $160 \mathrm{~m}^{2}$. Since the land lots are generally small, this living area should be divided into two floors. Moreover, most Thai people have a spiritual requirement. An attic space is a good place for the spiritual altar to keep the image of the Buddha. Therefore, the house should have two and a half floors, in addition to an open ground floor.

The site plan CFD results indicated that the air velocity on the first floor is higher than that on the second floor, because the ground floor is open, which allows the wind to travel freely. The first floor should be used as a living space that requires maximum ventilation. The bedrooms can then be located on the second floor. Hence, a suitable house for a Bangkok suburb can be designed as shown in Fig. 6. The ground floor, which is completely open and is not shown in the figure, is for service and car parking.

This design also uses the stack effect. The venting tower at the top of the roof, visible in Fig. 6(d), interrupts the wind current and creates a low pressure area [16]. The warmer indoor air, together with the low-pressure area at the top, draws cooler outdoor air into the house through the apertures in the lower part.

CFD was used to calculate airflow in the house with different design options. Fig. 7 shows an example of the airflow in and around the house on the first floor. The results 
provide great insight into the natural ventilation design. The following section summarizes the results obtained with numerous CFD computations:

1. The inlet aperture area should be around $20 \%$ of the floor area (or $30 \mathrm{~m}^{2}$ ) to achieve adequate natural ventilation for an acceptable comfort level. With such an aperture area, the air velocity in the first floor is around $0.4 \mathrm{~m} / \mathrm{s}$. The indoor air velocity distribution is rather uniform in the house we designed. When the aperture area is reduced to $13 \%$, the corresponding indoor air velocity becomes $0.3 \mathrm{~m} / \mathrm{s}$. Therefore, it is desirable to use a ceiling fan to increase the air velocity if a large aperture area is not feasible. Another option would be the use of a solar chimney to enhance the natural ventilation by buoyancy effect.

2. Equal aperture sizes in a house do not provide equal comfort levels. As shown in Fig. 8a, it is preferable to have a larger inlet aperture than a larger outlet aperture. This would reduce the stagnation zone in the house. A larger inlet aperture can also provide a larger ventilation rate. For example, with an inlet area of $32 \mathrm{~m}^{2}$ and an outlet area of $16 \mathrm{~m}^{2}$, the corresponding ventilation rate is $9.6 \mathrm{~m}^{3} / \mathrm{s}$. By swapping the inlet areas with those of the outlets, while keeping the total aperture area unchanged, the ventilation rate is reduced to $6.4 \mathrm{~m}^{3} / \mathrm{s}$.

3. An open plan allows for the highest wind velocity in the interior space (Fig. 8b). If the interior space needs to be partitioned, the number of walls should be as small as possible to allow wind to flow freely in the space.

4. Larger aperture areas do not necessarily provide better natural ventilation. Some apertures may shortcut the wind, as shown in Fig. 8c. In this design, the apertures in the east and west walls of the house should be closed for better ventilation. Since it is difficult to shade the east-facing and west-facing windows from the sun, shading and ventilation require the same design in this case.

5. The wind incident on a house is a resultant of the prevailing winds and the secondary winds from the houses upstream. In Bangkok, the prevailing wind direction is NNE. The secondary winds in our design were from the NNE for the left part of the house or the NNW for the right part of the house. If the house had a long room on the west, as shown in Fig. 8d, there would be a large stagnation zone in the east part of the long room, because the resultant wind direction of the prevailing and secondary wind is NNE. If the long room is located in the east part of the house, the resultant wind direction is from the north, in which the ventilation is much better (Fig. 8d).

6. The elevated floor allows more wind to flow through the houses (Fig. 8e), in addition to preventing damage to personal materials and furnishings in the event of a flood. An on-slab design actually creates a reverse flow that can greatly reduce the natural ventilation rate. Furthermore, it is possible to design a wind scoop on the ground level to take further advantage of the elevated floor, as illustrated in Fig. 8f. The wind scoop in our design was a stairway.

7. The study also demonstrated the buoyancy effect inside the house. With the assumption of a stagnant outside air, the CFD results showed that the buoyancy effect can generate a maximum air speed of $0.25 \mathrm{~m} / \mathrm{s}$ at areas close to a heat source, such as the stove in the kitchen. In the venting tower, the air velocity can be as high as 0.1 $\mathrm{m} / \mathrm{s}$. Apart from these situations, the air indoors was stagnant. Therefore, it can be concluded that stack effect is not strong enough to create a comfortable indoor 
environment, because the house is not tall enough and the heat gains are low. To design effective stack ventilation, a solar chimney seems a good option to explore.

8. If natural ventilation is used in the winter months, the total energy savings is less than $20 \%$ in a year. However, the indoor air quality in houses with natural ventilation would be significantly improved. This may be an important feature to justify natural ventilation design in Thailand.

\section{Discussion}

The proposed design has some constraints. The first costs may be high because of the elevated first floor. If the first floor is built on-slab, the ventilation rate would be reduced. This problem can be remedied by using a ceiling fan or solar chimney. The large aperture necessary for natural ventilation has some negative features, such as allowing outdoor air pollutants, outdoor noise, and insects to enter the house, reducing privacy, and creating potential security problems. However, in suburban areas, the air is much cleaner and there is less traffic noise. Mosquito nets and privacy and security screens could solve the other problems. Although the screens reduce the velocity of the wind, the wind speed is still high enough to shift the indoor condition into the comfort zone. Such screens are available on the market, but are beyond the scope of this research.

Another major constraint of this scheme is that people may not understand the overall ventilation concept and change their houses afterwards. For example, if they construct more walls to divide indoor spaces on the ground floor, the wind distribution throughout the neighborhood could change. The high velocity at ground level will no longer benefit their neighbors. The proposed scheme therefore cannot be executed without providing some fundamental knowledge or guidelines to the residents.

In addition to the wind-driven natural ventilation design addressed in this paper, it is possible to achieve natural ventilation through the buoyancy effect. Hirunlabh and his collegues [17-20]have published a number of papers on buoyancy-driven natural ventilation design for Thailand. The technologies used include the metallic solar wall [17], solar roof collector [18], solar chimney [19], and night radiant cooling [20]. The metallic solar wall can generate a ventilation rate as high as 1.65 ach in their model room. A similar ventilation rate has been found for the solar roof collector. The solar chimney seems the most effective having generated ventilation rates between 8 and 15 ach. Night radiant cooling can depress surface temperature by 1 to $6{ }^{\circ} \mathrm{C}$. The best designs may combine wind-driven ventilation with some of those technologies proposed by Hirunlabh and his colleagues. Such designs can be a subject of further studies.

\section{Conclusions}

This investigation explored the possibility for natural ventilation in houses in a hot and humid climate region, such as Bangkok, Thailand. The study shows that natural ventilation could be effective in the region during the winter (from December to February). Recent studies have found that the Thai people can live comfortably with much higher temperatures than westerners, so natural ventilation could also work in other seasons.

To achieve a comfortable indoor environment, natural ventilation should provide an indoor air velocity of $0.4 \mathrm{~m} / \mathrm{s}$. The corresponding total area of the inlet and outlet apertures should be about $40 \%$ of the total floor area. If the aperture area were decreased 
to $25 \%$, the indoor air velocity would be $0.3 \mathrm{~m} / \mathrm{s}$. A ceiling fan can be used to increase the air velocity in this case.

The prevailing wind direction in the winter in Bangkok is either from the NNE or the SSW. The house can still be oriented facing north-south to avoid excessive solar radiation. It is not necessary to align the house according to the prevailing wind direction. Since the land lots are small $\left(240-250 \mathrm{~m}^{2}\right)$, and the house floor area is large (160 $\mathrm{m}^{2}$ ), a rectangular house is not good for natural ventilation. This study found that it is better to use a square shape for the houses.

Consideration of the Thai culture and climate shows that it is better to design houses with two and a half floors. The first floor should be elevated to avoid floods and create better natural ventilation. The ground floor can serve as a service area and/or parking space. A stairway can serve as a wind scoop to augment the natural ventilation benefits of the elevated floor.

Other measures needed to enhance natural ventilation for houses in Bangkok suburbs include:

using larger inlet apertures than outlet apertures

keeping the indoor space as open as possible so that wind can travel freely

$\rightarrow$ closing the apertures on the east-facing and west-facing walls to avoid a shortcut

keeping long rooms in the east-facing part of the house

For houses two and a half floors high, the stack-effect is not strong enough to generate comfortable conditions indoors. Future house designs may combine the natural ventilation strategies considered here with several other developing technologies.

\section{References}

[1] ASHRAE, “Thermal Environmental Conditions for Human Occupancy," ASHRAE Standard 55a-1995, ASHRAE, Atlanta, 1995.

[2] A.B. Lovins, Air conditioning comfort: Behavioral and cultural issues, E Source, Inc., Boulder, Colorado, 1992.

[3] J.F. Busch, A tale of two populations: Thermal comfort in air-conditioned and naturally ventilated offices in Thailand, Energy in Buildings. 18 (1992) 235-249.

[4] H.J. Cowan, Handbook of architectural technology, Van Nostrand Reinhold, New York, 1991.

[5] Kwok, A.G. 1998. Thermal comfort in tropical classrooms, ASHRAE Transactions, 104(1).

[6] K. Jitkhajornwanich, A.C. Pitts, A. Malama, S. Sharples, Thermal comfort in transitional spaces in the cool season of Bangkok, ASHRAE Transactions, 1995, 1181-1193.

[7] N. Lechner, Heating, cooling, lighting: Design method for architects, John Wiley \& Sons, New York, 1991.

[8] K.S. Ashley, Natural ventilation cooling of buildings, Naval Civil Engineering Laboratory, Port Hueneme, California, 1984.

[9] J. Khedari, N. Yamtraipat, N. Pratintong, and J. Hirunlabh, Thailand ventilation comfort chart, Energy and Buildings, 32 (2000), 245-249.

[10] Thai Gypsum Products Public Company Limited, Energy efficient design of buildings in Thailand, Thai Gypsum Products Inc., Bangkok, 1995. 
[11] F. Moore, Environmental control system: Heating cooling lighting, McGraw-Hill Inc., Singapore, 1993.

[12] V. Olgyay, Design with climate: A bioclimatic approach to architectural regionalism, Princeton University Press, Princeton, 1963.

[13] CHAM, PHOENICS Version 3.1, CHAM Ltd, London, 1998.

[14] Z. Zhai, S.D. Hamilton, J. Huang, C. Allocca, N. Kobayashi, and Q. Chen, Integration of indoor and outdoor airflow study for natural ventilation design using CFD, Proceedings of the 21st AIVC Annual Conference on Innovations in Ventilation Technology, The Hague, The Netherlands, 2000.

[15] B. Givoni, Passive and low energy cooling of buildings, John Wiley \& Sons, Inc., New York, 1994.

[16] B. Evans, Letting fresh air back into buildings: The evolving state of the art of natural ventilation, Architecture, March (1989), pp. 72-77.

[17] J. Hirunlabh, W. Kongduang, P. Namprakai, and J. Khedari, Study of natural ventilation of houses by a metallic solar wall under tropical climate, Renewable Energy, 18 (1999) 109-119.

[18] J. Hirunlabh, S. Wachirapuwadon, N. Pratinthong, and J. Khedari, New configurations of a roof solar collector maximizing natural ventilation, Building and Environment 36 (2001) 383-391.

[19] J. Khedari, B. Boonsri, and J. Hirunlabh, Ventilation impact of a solar chimney on indoor temperature fluctuation and air change in a school building, Energy and Buildings, 32 (2000) 89-93.

[20] J. Khedari, J. Waewsak, S. Thepa, and J. Hirunlabh, Field investigation of night radiation cooling under tropical climate, Renewable Energy, 20 (2000) 183-193. 


\section{Figure Captions}

Fig. 1 Sketch of Thai houses (a) traditional and (b) modern

Fig. 2 Thermal comfort zone on a psychrometric chart

Fig. 3 Climate conditions of Bangkok and comfort zone on a bio-climatic chart

Fig. 4 Mean wind conditions of Bangkok at different time in the winter

Fig. 5 Plan view of the airflow around the houses (a) square shape and (b) rectangular shape $(\mathrm{m} / \mathrm{s})$

Fig. 6 The house design (a) the first floor plan, (b) the second floor plan, (c) the attic plan, and (d) the section

Fig. 7 Airflow in and around the house on the first floor level $(\mathrm{m} / \mathrm{s})$

Fig. 8 Design strategies obtained from the CFD simulations 


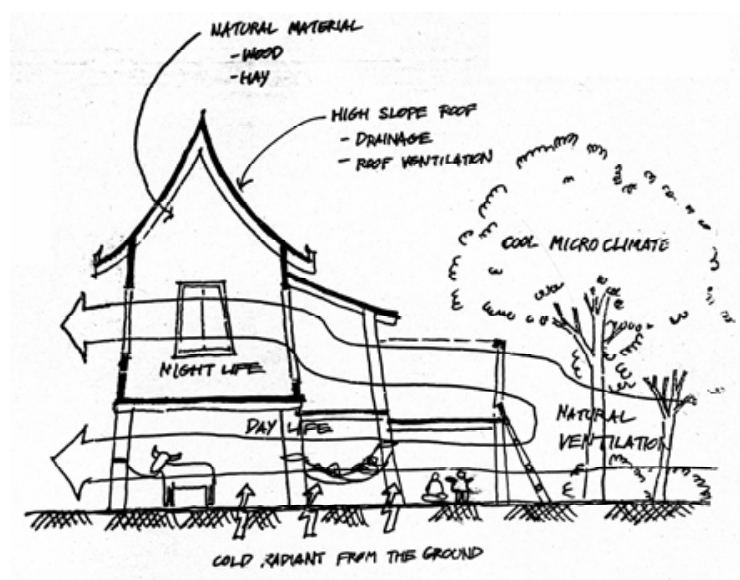

(a)

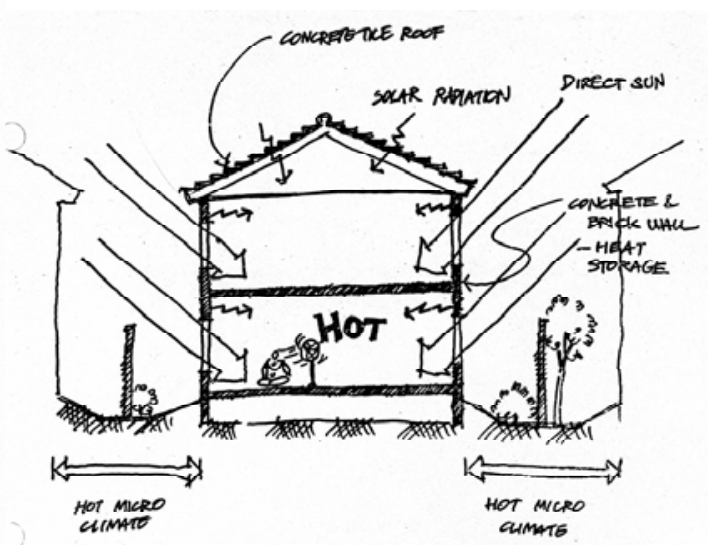

(b)

Fig. 1 Sketch of Thai houses (a) traditional and (b) modern

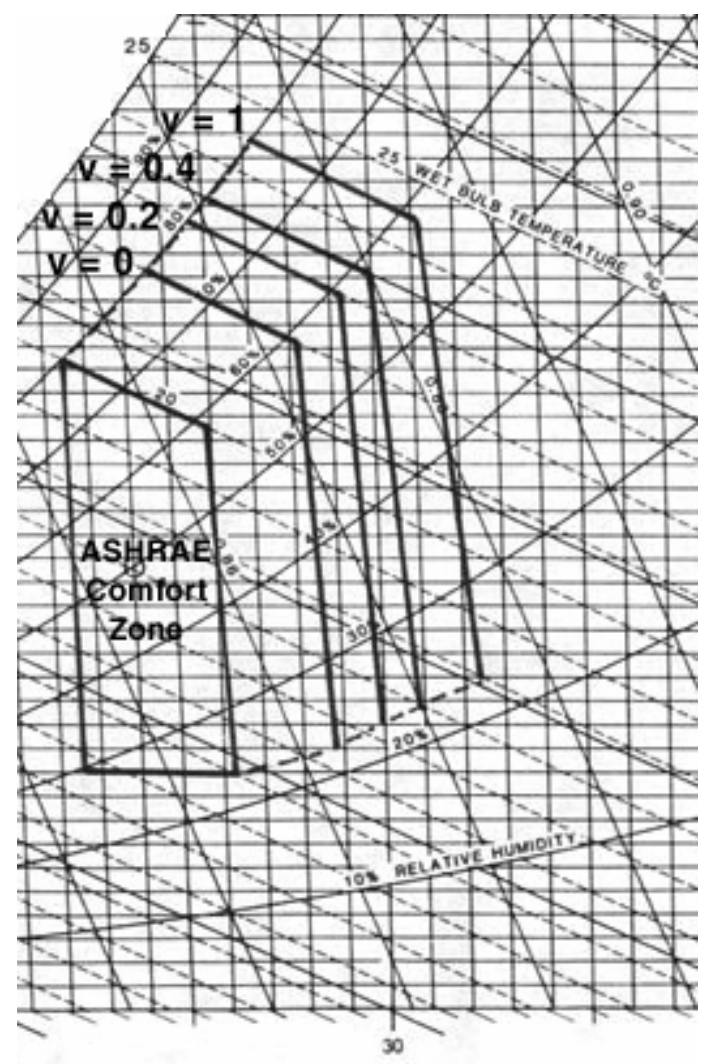

Fig. 2 Thermal comfort zone on a psychrometric chart 


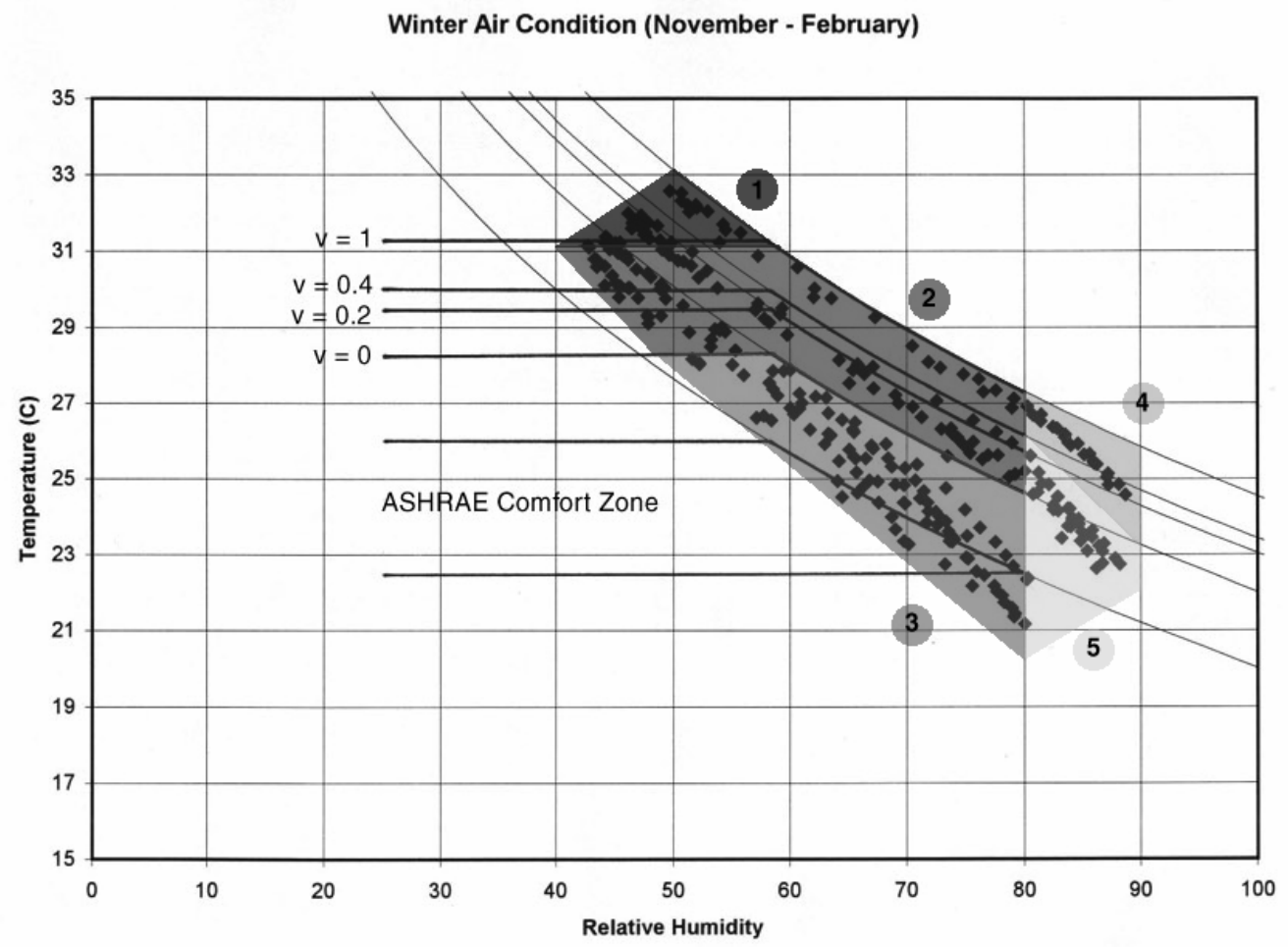

Fig. 3 Climate conditions of Bangkok and comfort zone on a bio-climatic chart

\begin{tabular}{|c|c|c|c|c|}
\hline Time & Nov & Dec & Jan & Feb \\
\hline 1 & & & & \\
\hline 2 & & & & \\
\hline 3 & & & & SSW/S \\
\hline $\begin{array}{l}4 \\
5\end{array}$ & \multirow{2}{*}{\multicolumn{2}{|c|}{ NNE/N }} & $\begin{array}{l}\mathrm{SSW} \\
0.4 \mathrm{~m} / \mathrm{s}\end{array}$ & $0.9 \mathrm{~m} / \mathrm{s}$ \\
\hline $\begin{array}{l}5 \\
6\end{array}$ & & $0.6 \mathrm{~m} / \mathrm{s}$ & & \\
\hline 7 & & & & \\
\hline \multicolumn{5}{|l|}{8} \\
\hline 9 & & & & \\
\hline 10 & & & ENE & S/2SW \\
\hline 11 & & & $2.0 \mathrm{~m} / \mathrm{s}$ & $2.3 \mathrm{~m} / \mathrm{s}$ \\
\hline 12 & & & & \\
\hline 13 & & & & \\
\hline 14 & \multicolumn{2}{|c|}{ NNE/N } & \multicolumn{2}{|c|}{ S/SSW } \\
\hline 15 & \multicolumn{2}{|c|}{$1.9 \mathrm{~m} / \mathrm{s}$} & \multirow{2}{*}{\multicolumn{2}{|c|}{$2.7 \mathrm{~m} / \mathrm{s}$}} \\
\hline 16 & & & & \\
\hline 17 & & & & \\
\hline $\begin{array}{l}18 \\
19\end{array}$ & & & \multicolumn{2}{|c|}{ SSW/S } \\
\hline 20 & & & \multicolumn{2}{|c|}{$1.4 \mathrm{~m} / \mathrm{s}$} \\
\hline 21 & \multicolumn{2}{|c|}{ N/NNE } & & \\
\hline 22 & \multirow{2}{*}{\multicolumn{2}{|c|}{$0.7 \mathrm{~m} / \mathrm{s}$}} & & \\
\hline 23 & & & & \\
\hline 24 & & & & \\
\hline
\end{tabular}

Fig. 4 Mean wind conditions of Bangkok at different time in the winter 


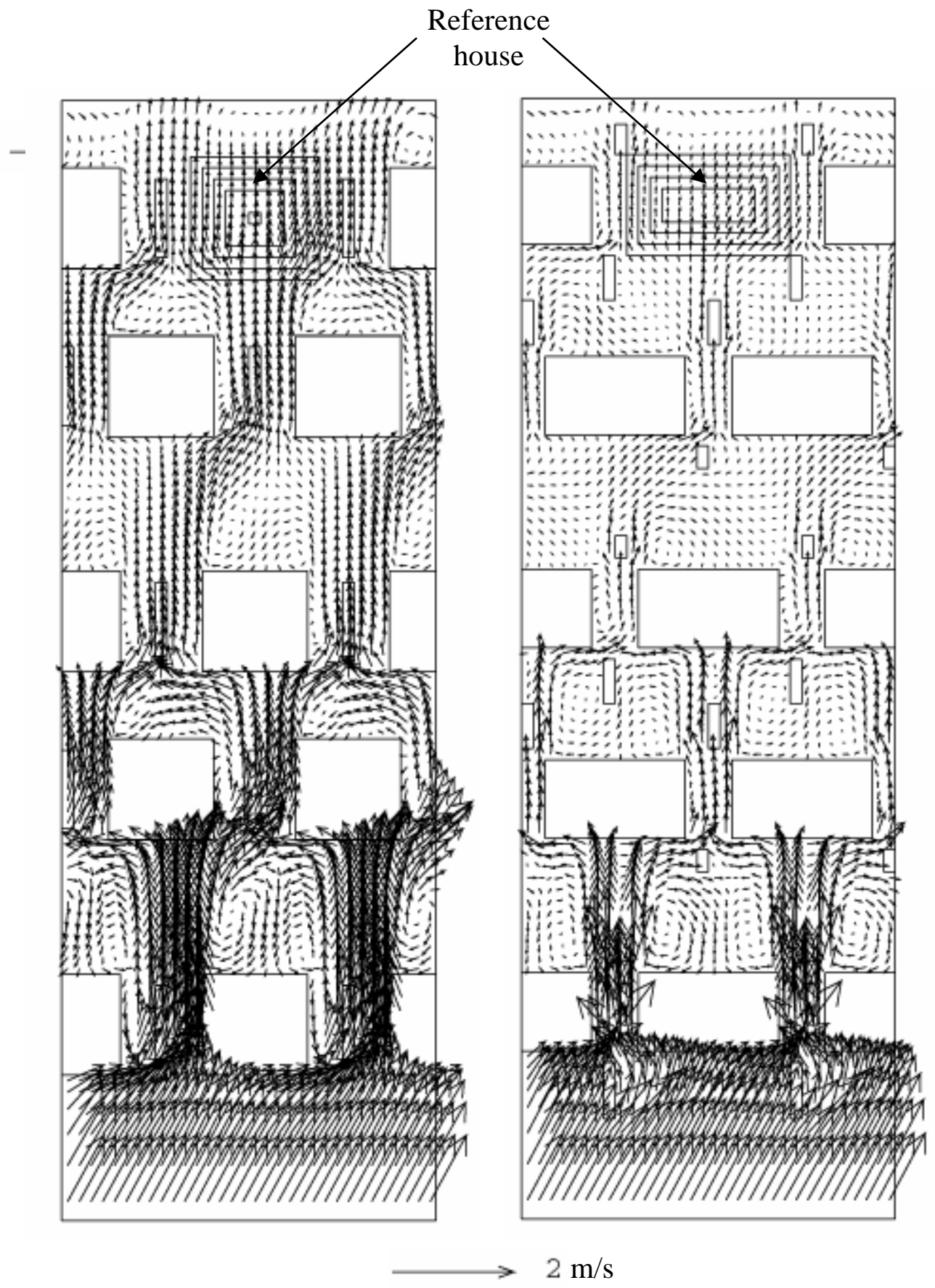

Fig. 5 Plan view of the airflow around the houses (a) square shape and (b) rectangular shape (m/s) 


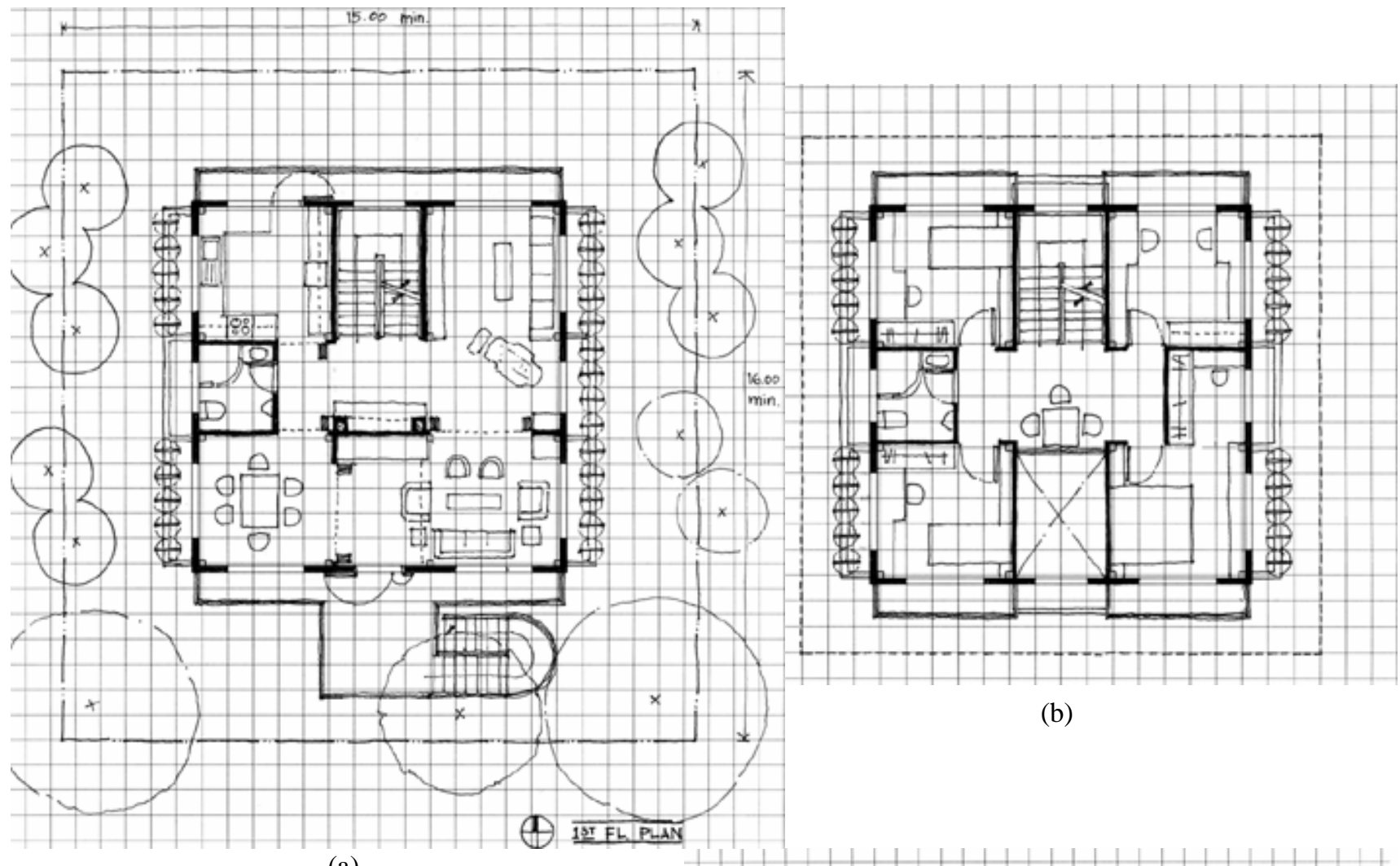

(a)

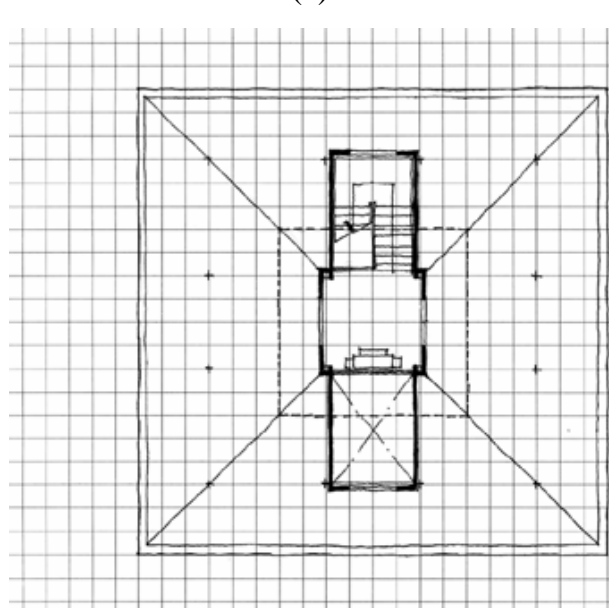

(c)

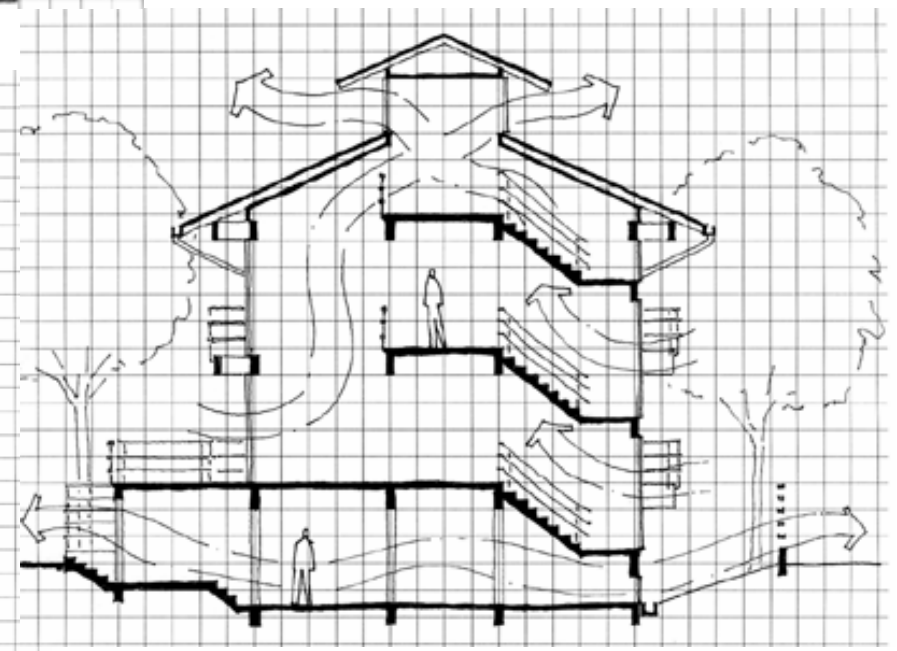

(d)

Fig. 6 The house design (a) the first floor plan, (b) the second floor plan, (c) the attic plan, and (d) the section. 


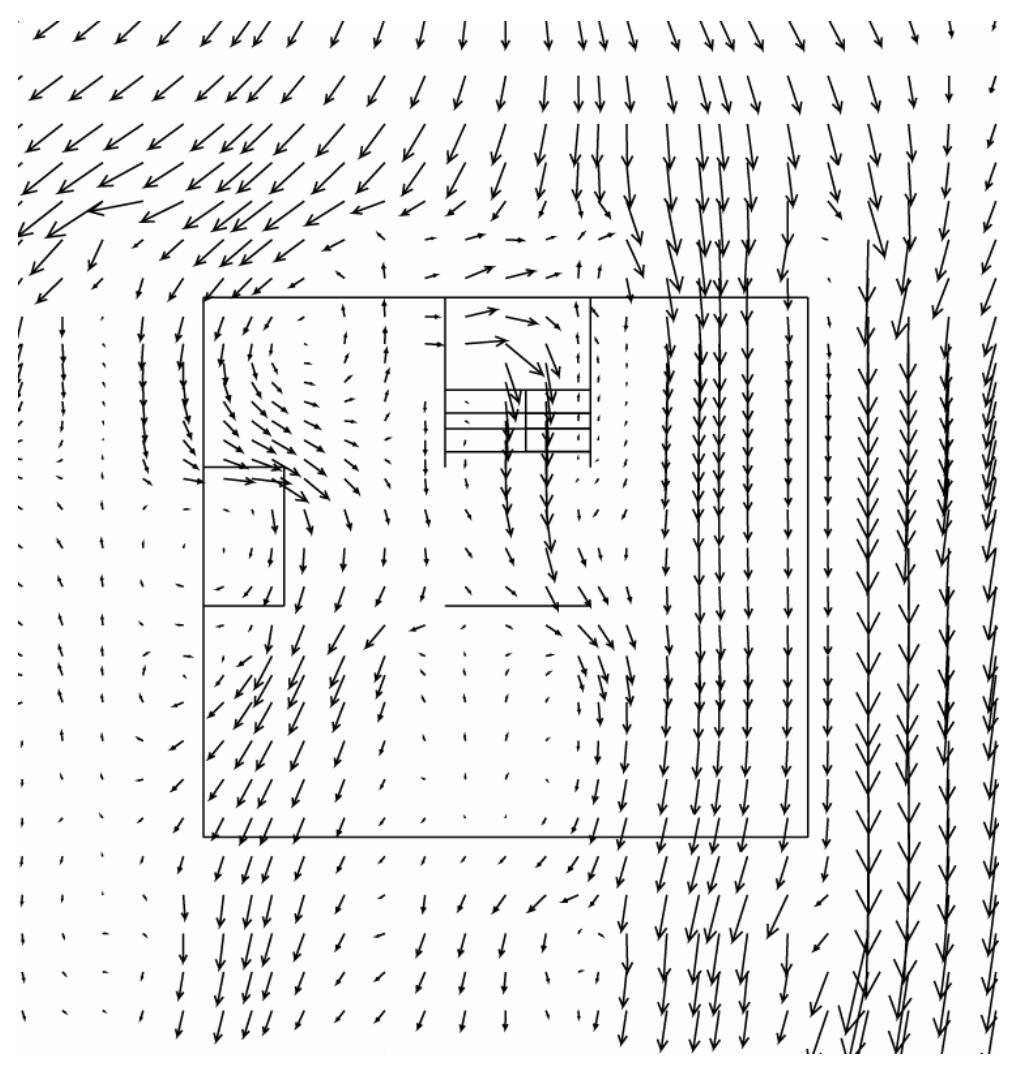

Fig. 7 Airflow in and around the house on the first floor level $(\mathrm{m} / \mathrm{s})$ 

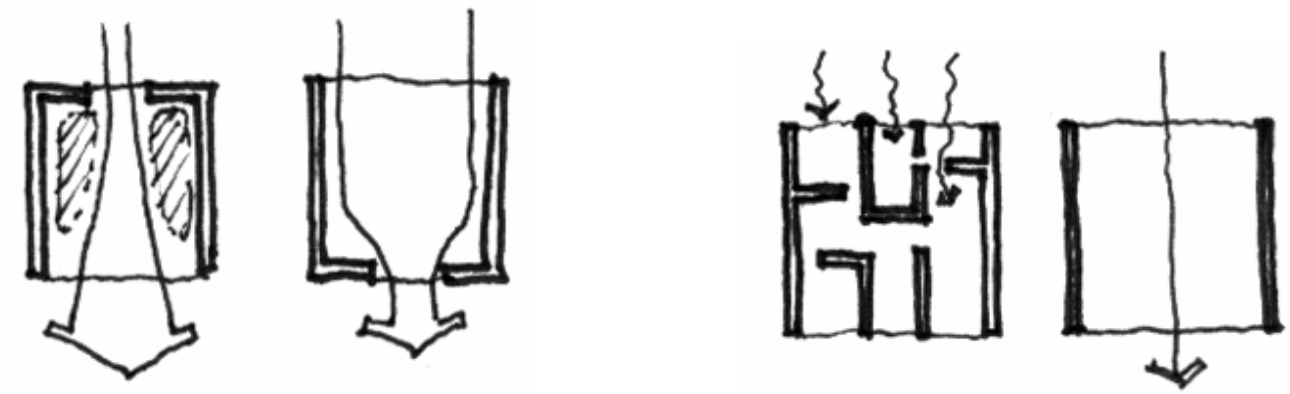

(a)

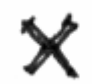

(b)
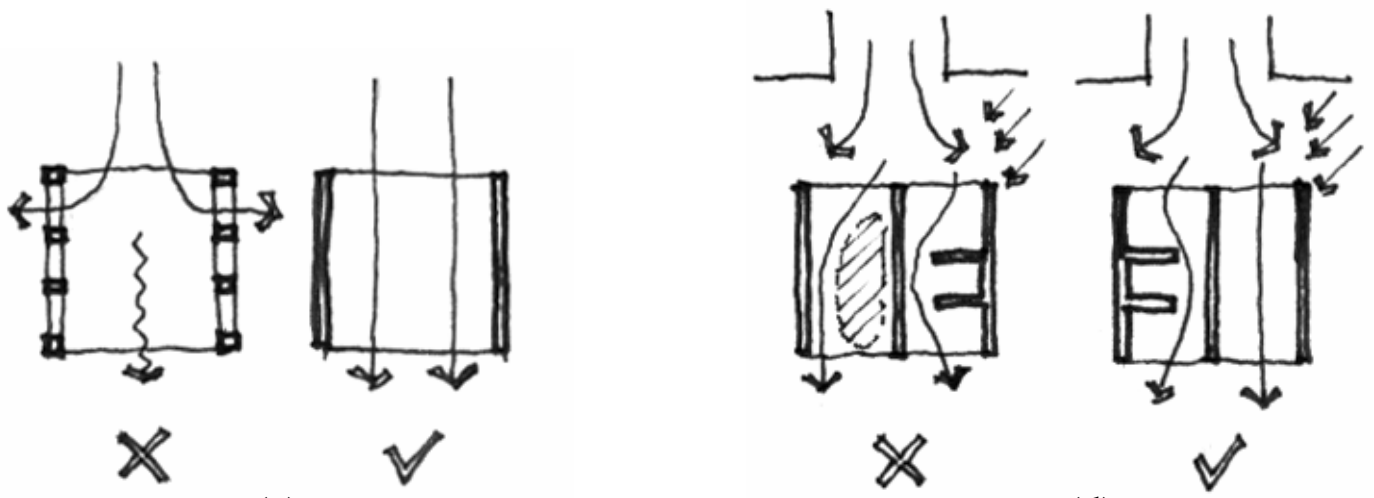

(c)

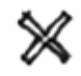

(d)
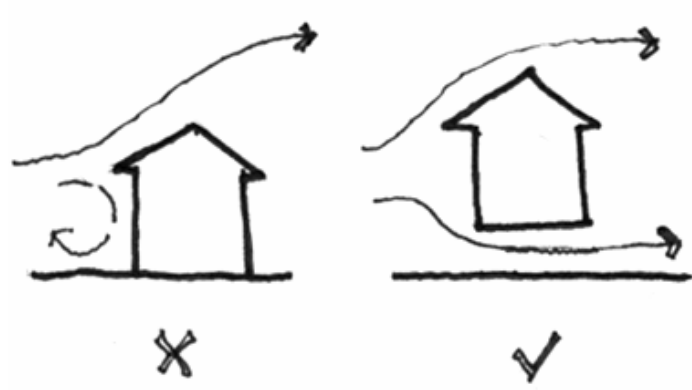

(e)
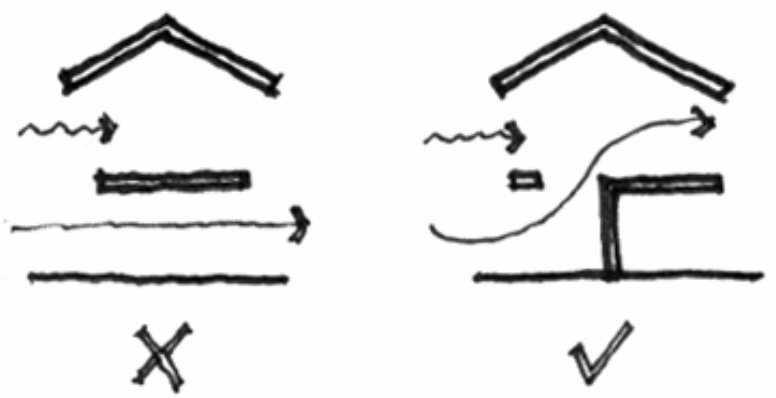

(f)

Fig. 8 Design strategies obtained from the CFD simulations 